\title{
Inequities in reporting asbestos-related lung cancer: influence of smoking stigma and physician's specialty, workload and role perception
}

\author{
P Verger, ${ }^{1,2}$ S Arnaud, ${ }^{1}$ S Ferrer, ${ }^{1}$ G Iarmarcovai, ${ }^{1}$ M-L Saliba, ${ }^{1,2}$ A Viau, ${ }^{3}$ M Souville ${ }^{4}$
}

${ }^{1}$ Southeastern Health Regional Observatory (ORS PACA), Marseilles, France; ${ }^{2}$ French Institute of Health and Medical Research (INSERM UMR379),

Marseilles, France; ${ }^{3}$ Grand Conseil de la Mutualité-

Mutuelles de Provence, Marseilles, France; ${ }^{4}$ Aix Marseille University, Laboratoire de Psychologie Sociale, UPRES EA849, Aix-en-Provence, France

Correspondence to: Pierre Verger, Observatoire Régional de la Santé PACA INSERM UMR 379

23 rue Stanislas Torrents, 13006 Marseille, France; verger@marseille.inserm.fr

Accepted 28 September 2007 Published Online First 10 October 2007

\section{ABSTRACT}

Objectives: To study physician barriers to workers' compensation claims for asbestos-related cancers, focusing on smokers' stigma and physicians' speciality and role perception.

Methods: Cross-sectional telephone study of 486 randomly-selected general practitioners (GPS) and pulmonologists in south-eastern France. Standardised questionnaires explored their behaviour, attitudes and practices in the field of occupational health and their responses to a case vignette of a lung cancer patient with long-term occupational asbestos exposure. Randomised subgroups of GPs and pulmonologists heard alternative versions varying only as regards the worker's smoking status. We studied factors associated with the recommendation that the case vignette patient file a compensation claim with simple and multiple logistic regressions

Results: The response rate was $64.4 \%$ among GPs and $62.5 \%$ among pulmonologists. Recommending the filing of an occupational disease claim was significantly associated in multiple logistic regressions with speciality (OR 4.46; $95 \% \mathrm{Cl} 2.38$ to 8.37 , for pulmonologists vs GPs), patient's smoking status (OR 3.15; 95\% Cl 2.11 to 4.70 , for non-smokers vs smokers), physician's workload (OR 1.83; $95 \%$ Cl 1.17 to 2.88 , for $\leqslant 25$ consultations per day vs $>25$ ) and role perception (OR 2.00; 95\% Cl 1.22 to 3.27 , for those who considered completing occupational disease medical certificates to be part of their role vs those who did not).

Conclusions: The results of this French study appear applicable to various countries and contexts. To make physicians and especially GPs more aware of occupational health and smoking stigma, officials and educators must give these topics higher priority during initial training and continuing medical education. Tools and equipment that take time constraints into account should be developed and disseminated to help physicians manage occupational diseases.

The carcinogenicity of asbestos has long been established. Evidence of a dose-effect relationship between occupational asbestos exposure and lung cancer was first published in $1955^{1}$ and has continued to accumulate. ${ }^{2}$ France did not ban the manufacture and use of asbestos until 1997. ${ }^{3} \mathrm{~A}$ 2003 report estimated that each year 2086-4172 lung cancer deaths and another 540-580 deaths from mesothelioma in France are attributable to asbestos. $^{4}$

The burden of this epidemic is substantial and includes medical care, social consequences and costs. Compensation for occupational diseases
(ODs) in France is based on an insurance system: the employer who created the risk bears the financial burden of compensation and must reimburse the health insurance funds for the costs. ${ }^{35}$ Patients have lower or no co-payments and receive daily disability allocations higher than for nonwork-related disease. The compensation procedure requires that the patient file a claim with the health insurance fund, accompanied by a medical certificate. In reality, medical and administrative practices unfairly restrict victims' access to compensation. $^{34}$ It is estimated that only $8-18 \%$ of asbestos-related lung cancers and about $50 \%$ of mesotheliomas are recognised and compensated in France. ${ }^{4}$ Similar rates are encountered in other countries, ${ }^{6-9}$ including the United Kingdom. ${ }^{8}$

Physicians play an important role in recognising and reporting ODs in many countries, ${ }^{3-10}$ by taking effective occupational histories and identifying possible links between disease and occupation. ${ }^{10}$ In France, they must complete the medical certificate mandatory for the claims process. Besides barriers to filing OD claims at the patient level, ${ }^{10}$ there are multiple but little-studied barriers at the physician level. ${ }^{10-14}$ These include physicians' attitudes to lifestyle factors, especially smoking (the leading cause of lung cancer, a multifactorial disease), ${ }^{6}{ }^{14}$ their perception of their role in occupational health $(\mathrm{OH})^{812}$ and their workload. ${ }^{13}$

Between November 2006 and February 2007 we conducted a cross-sectional telephone survey of private general practitioners (GPs) and pulmonologists in south-eastern France, aimed at studying medical barriers to OD claims. This study focused on asbestos-related lung cancer and tested three hypotheses: (1) physicians' recommendations to patients to file OD claims for probable asbestosrelated lung cancers differ according to patients' smoking history; (2) GPs' recommendations differ from those of pulmonologists; and (3) physicians who do not recommend filing claims may think that it is not their role.

\section{METHODS}

\section{Sample}

We stratified the sampling base $(\mathrm{n}=5500)$ for GPs according to gender, year of birth $(\leqslant 1957,>1957)$ and size of practice area ( $<15000,15000-99999$, $\geqslant 100000$ inhabitants) and randomly selected 822 GPs in the resulting strata with the aim of obtaining a final sample of 400 GPs. We randomly selected 193 of the 266 pulmonologists practising in south-eastern France to obtain a final sample of 
100 pulmonologists; 59 (30.6\%) worked mainly at hospitals and $134(69.4 \%)$ in private practice.

\section{Questionnaire}

We developed a 94-item questionnaire based on an earlier qualitative study of the practices and attitudes toward $\mathrm{OD}$ and $\mathrm{OH}$ of 19 GPs, occupational physicians and other professionals in this field. ${ }^{14}$ The questionnaire was then pilot tested with 20 GPs for length, clarity and suitability. It covered the physicians' professional characteristics, practices, attitudes and self-perceived role in the area of OD (see appendix). It also included a case vignette about a 50-year-old man diagnosed with lung cancer after 20 years' employment at a French shipyard well known for high asbestos exposure levels. We administered two versions ( $\mathrm{A}$ or $\mathrm{B}$ ), differing only regarding the patient's smoking status, to randomly selected subgroups of GPs and pulmonologists. Participants were asked these questions: "Would you recommend to the patient that he file a worker's compensation claim for lung cancer?" (yes/no); "If not, why not?"; "Because you do not think you have sufficient information to decide?" (yes/no); "Because this is an administrative task?" (yes/no); "Because this is a pulmonologist or oncologist's job, not yours?" (yes/no), for GPs only; "Because it is a GP's job and not yours?" (yes/no), for pulmonologists only; "Because this is the occupational physician's job and not yours?" (yes/no), for GPs and pulmonologists.

\section{Survey procedure}

Professional interviewers used a computer-assisted telephone interview system to question the doctors. Before concluding that a physician could not be reached, interviewers had to make 15 attempts at different times of the day and on different days.

\section{Statistical analysis}

We used the $\chi^{2}$ and Student $t$ statistics for univariate comparisons of qualitative and quantitative variables, respectively. We performed a stepwise multiple logistic regression to test factors associated with the dependent variable "recommending the patient file a claim"; age, gender and case vignette status (A or B) were forced in the model. We tested all of the practices, attitudes and self-perceived role variables described in the appendix ( $p$ entry $\leqslant 0.20 ; p$ exit $>0.05$ ) in two different models, one (1) of which included speciality (GPs/pulmonologists), while the other (2) did not. We used the Hosmer and Lemeshow statistic to test model fit. The analysis was performed with SAS v9.1.

\section{RESULTS}

We reached 674 of 822 GPs, 57 of whom were ineligible (ill, retired or not GPs); 391 of 617 eligible GPs (63.4\%) agreed to participate. We reached 182 of 193 pulmonologists, 30 of whom were ineligible (other speciality, not practicing); 95 of 152 pulmonologists $(62.5 \%)$ agreed to participate.

Table 1 summarises the participants' demographic characteristics and behaviour, attitudes and opinions about $\mathrm{OH}$. Most of these variables differed significantly between GPs and pulmonologists as a whole, but the two subgroups of GPs did not differ significantly from one another, nor did the two subgroups of pulmonologists (results not shown).

The percentage of GPs who would recommend filing a claim was significantly higher among those asked about a nonsmoking patient (table 2). On the other hand, patient smoking status did not affect recommendations by pulmonologists overall, and recommendations were similar for hospital-based specialists and those in private practice $(88.2 \%$ vs $82.0 \%$, respectively; $p=0.42)$. The GPs who would not recommend filing a claim (table 2) mainly considered that it was not their role but that of the pulmonologist or occupational physician. Only a minority of pulmonologists who would not recommend filing a claim considered it the role of the GP or occupational physician.

Finally, the multiple logistic model (1) showed a significant association between recommending filing an OD claim and speciality, patient smoking status, daily number of consultations, experience with asbestos-related cancer, and agreement that completing $\mathrm{OD}$ medical certificates is part of the physician's role. Model (2) (specialty not included) showed the same associations as well as significant associations with thinking that not knowing reporting criteria is a barrier to reporting $\mathrm{OD}$, and a continuing medical education course in $\mathrm{OH}$ (table 3).

\section{DISCUSSION \\ Effects of smoking}

Our results confirm our first hypothesis, that patients' smoking status modifies physicians' behaviour in recommending filing occupational lung cancer claims, but only among GPs. Several factors may explain this result. First, the nature and complexity of multifactorial diseases is poorly understood even among doctors, ${ }^{15}$ and GPs may be more likely than specialists to be unaware that the combination of cigarette smoking and asbestos exposure greatly enhances the risk of lung cancer. ${ }^{16}$ GPs may also be unaware that lung cancer may be attributable to asbestos exposure in the absence of radiographic or histologic evidence of asbestosis: ${ }^{17}$ the case vignette did not mention any radiological or histological signs of asbestos exposure. GPs may also be unaware of or misunderstand the legal principles underlying compensation in France. The French system relies on the "presumption of imputability": when the disease is registered on a list of compensable ODs (as asbestos-related lung cancer is), the victim does not need to prove a causal relationship between occupational exposure and the disease ${ }^{3}$ if specific conditions are met (eg, delay between end of exposure and date of diagnosis of the disease). This principle implies that, as in other countries, the contribution of individual lifestyle factors is irrelevant to the usual compensation procedure. ${ }^{18}$ Moreover, physicians are not required to decide that a given lung cancer is attributable to an occupational cause to recommend that the patient file a claim. Certainty about attribution is an extremely difficult question for experts, let alone generalists, for diseases that lack unique occupational characteristics. The National Health Insurance Fund, to which the report is addressed, decides attribution, relying on an investigation at the company, if it still exists, on the list of companies that previously used asbestos, or sometimes on expert groups. The spirit of the French law indicates that it is preferable for patients to overreport, that is, to report even though the attribution of lung cancer to occupational exposure to asbestos is uncertain. Finally, GPs may have discriminatory attitudes towards patients with lung cancer who are or were smokers: these patients often experience stigma, due in part to the association between smoking and lung cancer (the cancer is perceived as a self-inflicted injury ${ }^{19}$ and a logical sanction ${ }^{20}$ ). Physicians may underestimate the influence of environmental factors and attribute diseases instead to factors such as behaviour (attribution bias) ${ }^{21}$ In this case, as in other medical areas, ${ }^{22-25}$ negative attitudes may modify physicians' behaviour and thus lead them to neglect specific actions affecting patients' rights. 
Table 1 Demographic and professional characteristics of the sample and attitudes and opinions in the field of occupational health $(n=486$ physicians)

\begin{tabular}{|c|c|c|c|c|}
\hline Variables & & $\begin{array}{l}\text { General } \\
\text { practitioners } \\
(n=391)\end{array}$ & $\begin{array}{l}\text { Pulmonologists } \\
(\mathrm{n}=95)\end{array}$ & $\begin{array}{l}\text { GPs vs } \\
\text { pulmonologists } \\
\text { (p Value) }\end{array}$ \\
\hline Mean age (years, SD) & & $51.6(7.5)$ & $51.0(7.5)$ & 0.49 \\
\hline \multirow[t]{2}{*}{ Gender (\%) } & Men & 76.2 & 72.6 & 0.47 \\
\hline & Women & 23.8 & 27.4 & \\
\hline \multirow[t]{3}{*}{ Size of urban unit (1000 inhabitants) } & $<15$ & 34.5 & - & - \\
\hline & $15-100$ & 31.7 & & \\
\hline & $>100$ & 33.8 & & \\
\hline Number of years of practice (years, SD) & & $21.2(8.3)$ & $21.1(8.2)$ & 0.88 \\
\hline \multirow[t]{3}{*}{ Daily number of consultations (\%) } & $<15$ & 17.4 & 30.3 & 0.006 \\
\hline & $15-25$ & 51.8 & 51.7 & \\
\hline & $>25$ & 30.7 & 18.0 & \\
\hline \multirow[t]{2}{*}{ Asks questions about past exposure (\%) } & Yes & 50.6 & 90.5 & $<10^{-3}$ \\
\hline & No & 49.4 & 9.5 & \\
\hline \multirow[t]{2}{*}{ Number of medical certificates in the past 5 years $(\%)^{*}$} & $\leqslant 2$ & 58.1 & 16.8 & $<10^{-3}$ \\
\hline & $>2$ & 41.9 & 83.2 & \\
\hline \multirow[t]{2}{*}{ Does not know reporting criteria (\%) } & Yes & 77.5 & 47.4 & $<10^{-3}$ \\
\hline & No & 22.5 & 52.6 & \\
\hline \multirow{2}{*}{$\begin{array}{l}\text { Has already had a continuing medical education course } \\
\text { in the field of } \mathrm{OH}(\%)\end{array}$} & Yes & 16.9 & 41.1 & $<10^{-3}$ \\
\hline & No & 83.1 & 58.9 & \\
\hline \multirow[t]{2}{*}{ Has had patients with asbestos-related cancers (\%) } & Yes & 11.8 & 40.0 & $<10^{-3}$ \\
\hline & No & 88.2 & 60.0 & \\
\hline \multirow{2}{*}{$\begin{array}{l}\text { Feels able to answer patients' questions about } \\
\text { occupational health (\%) }\end{array}$} & Yes & 63.4 & 81.1 & $<10^{-3}$ \\
\hline & No & 36.6 & 18.9 & \\
\hline \multicolumn{5}{|l|}{ Opinions on barriers to reporting of $\mathrm{OD}$} \\
\hline \multirow[t]{2}{*}{ Complexity of the lists of compensable OD (\%) } & Yes & 79.8 & 52.6 & $<10^{-3}$ \\
\hline & No & 20.2 & 47.4 & \\
\hline \multirow[t]{2}{*}{ Lack of knowledge of administrative procedures (\%) } & Yes & 79.8 & 60.0 & $<10^{-3}$ \\
\hline & No & 20.2 & 40.0 & \\
\hline \multirow[t]{2}{*}{ Lack of time (\%) } & Yes & 47.1 & 48.4 & 0.81 \\
\hline & No & 52.9 & 51.6 & \\
\hline \multicolumn{5}{|l|}{ Physician's role includes } \\
\hline \multirow[t]{2}{*}{ Detecting an OD (\%) } & Yes & 77.5 & 88.4 & 0.02 \\
\hline & No & 22.5 & 11.6 & \\
\hline \multirow[t]{2}{*}{ Completing OD medical certificates $(\%)^{*}$} & Yes & 74.9 & 93.7 & $<10^{-3}$ \\
\hline & No & 25.1 & 6.3 & \\
\hline
\end{tabular}

${ }^{*}$ Certificates for the report of occupational diseases to the French national health insurance fund.

\section{Differences between GPs and pulmonologists}

As we had hypothesised, GPs differed significantly from pulmonologists in their attitudes, behaviours and practices (table 1), especially claim recommending behaviour, which was much more frequent in pulmonologists (OR 4.46, table 3). Previous studies showed that GPs feel constraints in addressing $\mathrm{OH}$ problems and assign low priority to them; ${ }^{12}$ they also perceive that the tasks necessary for reporting ODs are too complex. ${ }^{13}$

Multiple regression model 2 showed that when speciality was removed from the model, two other explicative variables became significant: "thinks that not knowing reporting criteria is a barrier to reporting OD" and "has taken a CME course in OH" (table 3). This suggests that differences between pulmonologists and GPs probably reflect GPs' inadequate knowledge and lack of training in $\mathrm{OH}$. Numerous articles have pointed out the inadequate training of GPs and the insufficient curriculum time allocated to $\mathrm{OH}$ in medical schools in France ${ }^{26}$ and elsewhere. ${ }^{12} 132728$

\section{Limited role and workload}

Our results also confirmed, although to differing degrees according to speciality, our third hypothesis: most GPs and some pulmonologists who answered they would not recommend filing an OD claim in the case vignette considered that it was not their role to make such a recommendation (table 2 ). They did not think completing an OD medical certificate was part of their job, as illustrated by the significant association between the reverse opinion and recommending that the patient file a claim in both multiple logistic regression models (table 3 ).

We also found that physicians with the highest workload (proxy: number of daily consultations in the preceding week) recommended filing a claim significantly less often, independent of patient's smoking status and speciality (table 3). Reports on barriers to managing $\mathrm{OH}$ problems in general practice mention time constraints inconsistently. ${ }^{12}{ }^{13}$ To the best of our knowledge, a direct relationship between physicians' practices in the $\mathrm{OH}$ field (such as recommending claims) and their workload has not been shown previously, although such a relationship has been suggested in other fields. ${ }^{29}{ }^{30}$ Recommending that patients file an OD claim may be time consuming: in France, if the patient decides to file a claim, the physician must complete an $\mathrm{OD}$ medical certificate, a somewhat tedious job requiring, among other things, identifying and getting access to the right list of compensable asbestos-related diseases. 
Table 2 Results of the case vignette

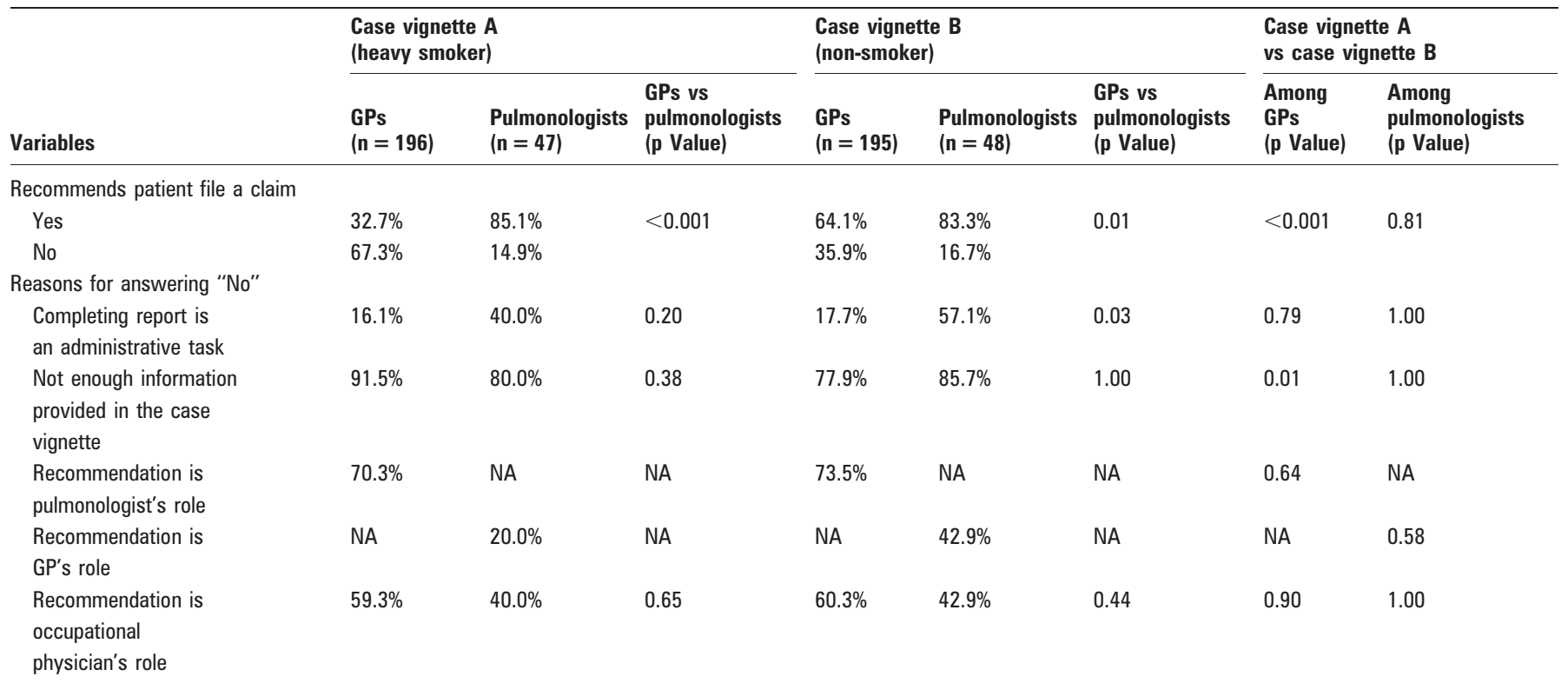

Percentage of physicians (general practitioners and pulmonologists) who answered yes/no to the question "Do you recommend that your patient file an occupational disease claim to the health insurance fund?" and reasons reported for a negative response ( $n=486$ physicians). NA, not applicable.

\section{Limitations of the study}

Because this was a cross-sectional study, we cannot draw causal inferences from the associations we observed. Nonetheless, the quasi-experimental design we followed in applying the case vignette and the comparability of the two GP subgroups and the two pulmonologist subgroups boost our findings. Although the conception and wording of the case vignettes were as close as possible to a real situation, this method cannot ensure that responses reflect the way GPs would behave in a real situation. ${ }^{31}$

Although GPs often are unwilling or unprepared to recommend reporting of these asbestos-related lung cancers, they do refer these patients with lung cancer to pulmonary specialists for medical management. These referrals should increase the chances the disease will be reported. Nonetheless, it is a fact that lung cancers related to asbestos are massively underreported in France and elsewhere. Even though the vast majority of pulmonologists questioned in this study reported that they would recommend reporting the disease to the patient in the vignette, it is likely that they do not do so routinely in their practice or that they are not always able to help the patient do so. We might reasonably think therefore that the reporting rate would rise if GPs also made this recommendation,

Table 3 Factors associated with "recommending that the patient file a compensation claim for lung cancer" (case vignette): multiple logistic regression ( $n=486$ physicians)

\begin{tabular}{|c|c|c|c|}
\hline Explanatory variables* & & $\begin{array}{l}\text { Model (1) including the variable } \\
\text { "physician speciality" } \dagger \\
\text { Odds ratio (95\% CI) }\end{array}$ & $\begin{array}{l}\text { Model (2) not including the variable } \\
\text { "physician speciality" } \$ \\
\text { Odds ratio }(95 \% \mathrm{Cl}) \S\end{array}$ \\
\hline Speciality & GPs & $1.00(-)$ & $-(-)$ \\
\hline Mean age (continuous) & & $0.99(0.96$ to 1.02$)$ & $0.98(0.95$ to 1.01$)$ \\
\hline \multirow[t]{2}{*}{ Gender (\%) } & Women & $1.00(-)$ & $1.00(-)$ \\
\hline & Men & $0.97(0.60$ to 1.57$)$ & $0.95(0.59$ to 1.52$)$ \\
\hline \multirow[t]{2}{*}{ Number of daily consultations } & $>25$ & $1.00(-)$ & $1.00(-)$ \\
\hline & $\leqslant 25$ & $1.83(1.17$ to 2.88$)$ & $2.12(1.37$ to 3.31$)$ \\
\hline \multirow[t]{2}{*}{ Has taken a CME course in occupational health** } & No & $-(-)$ & $1.00(-)$ \\
\hline & Yes & & 1.80 (1.09 to 2.98$)$ \\
\hline Has had patients with asbestos-related cancers & No & $1.00(-)$ & $1.00(-)$ \\
\hline $\begin{array}{l}\text { Thinks that not knowing reporting criteria is a } \\
\text { barrier to reporting } 0 \mathrm{D} \dagger \dagger \\
\text { Agrees that completing } \mathrm{OD} \text { medical certificates is } \\
\text { part of role } \dagger\end{array}$ & Yes & $2.00(1.22$ to 3.27$)$ & $2.23(1.37$ to 3.62$)$ \\
\hline
\end{tabular}

*Other variables tested in simple logistic regressions and not significant at $p=0.20$ were not entered in either model: size of urban unit, asks questions about past working conditions, number of occupational disease medical certificates completed in the past 5 years, feels able to answer patients' questions about $\mathrm{OH}$, thinks that lack of knowledge of administrative procedures is a barrier to reporting $\mathrm{OD}$, thinks that complexity of the lists of compensable occupational diseases is a barrier to reporting $0 \mathrm{D}$, thinks that lack of time is a barrier to reporting OD, thinks that detecting an occupational disease is part of role; †Hosmer and Lemeshow test: $p=0.88$; $\$$ Hosmer and Lemeshow test: $p=0.56$; $\S 95 \% \mathrm{Cl}, 95 \%$ confidence interval; $\uparrow \mathrm{A}$ : smoker, B: non-smoker; ${ }^{*} \mathrm{CME}$, continuing medical education; ††occupational diseases. 


\section{Main messages}

- Asbestos-related lung cancers and to a lesser degree mesotheliomas are under-recognised and under-compensated in many countries throughout the world.

- Physicians play an important role in many countries in recognising and reporting occupational diseases, steps necessary for workers' compensation claims.

- Patients' smoking status modified GPs' behaviour in recommending occupational asbestos-related lung cancer claims.

- Pulmonologists and GPs differed according to this recommendation and various attitudes reflecting differences in knowledge, training, and role perception in occupational health.

- Workload was a significant barrier to this recommendation, suggesting a lack of adequate tools to deal with practical questions raised by this recommendation.

\section{Policy implications}

- Physicians and especially general practitioners must be made more aware of occupational health, occupational diseases reporting and compensation procedures by increasing the priority of occupational health during initial training and continuous medical education.

- Tools and equipment, such as self-report screening questionnaires to improve patients' recollection of occupational exposures while taking consultation time constraints into account should be developed and disseminated to help physicians manage occupational health problems.

as it is normally incumbent on them to do in France, and if they explained to their patients its value and procedures. This might well encourage hesitant patients to file claims. It was in this spirit that the 2004 public health law in France strengthened the GP's role in the coordination of patients' medical and social management.

\section{CONCLUSION}

Although the French occupational compensation system is relatively protective for workers, frequent inequities remain in reporting and thus compensating severe ODs, including cancers. Our study suggests that reasons for this are linked in part to physicians' workload, knowledge and training in the field of $\mathrm{OH}$, their perceptions of their role, which differ according to speciality, and finally the special stigma associated with smokers with lung cancer. These attitudes may well concern not only patients with lung cancer but also those with other cancers or other multifactorial diseases with a leading behavioural cause. The literature suggests that these results apply to other countries and diseases.

Physicians and especially GPs must be made more aware of $\mathrm{OH}, \mathrm{OD}$ reporting and compensation procedures. Increasing the priority of $\mathrm{OH}$ during initial training and continuous medical education might help change this, as might insistence on attitudinal aspects. Moreover, tools and equipment, such as selfreport screening questionnaires to improve patients' recollection of occupational exposures ${ }^{10}$ while taking time constraints into account, should be developed and disseminated to help physicians manage $\mathrm{OH}$ problems.

Acknowledgements: We thank Jo Ann Cahn for reading the manuscript and improving our English.

Funding: This study received support from the call for proposals "Health at Work" 2004, of the Ministère de l'emploi, du travail et de la cohésion sociale/Direction des Relations du Travail.

Competing interests: None.

\section{REFERENCES}

1. Doll R. Mortality from lung cancer in asbestos workers. Br J Ind Med 1955;12:81-6.

2. Peto J, Hodgson JT, Matthews FE, et al. Continuing increase in mesothelioma mortality in Britain. Lancet 1995;345:535-9.

3. Thebaud-Mony A. Justice for asbestos victims and the politics of compensation: the French experience. Int J Occup Environ Health 2003;9:280-6.

4. Imbernon H. Estimation du nombre de cas de certains cancers attribuables à des facteurs professionnels en France. Saint-Maurice: Institut de Veille Sanitaire, Département Santé Travail, 2003:28.

5. Aubrun JC, Binet S, Bozec C, et al. Occupational cancer in France: epidemiology, toxicology, prevention, and compensation. Environ Health Perspect 1999;107:245-52.

6. Barroetavena MC, Teschke K, Bates DV. Unrecognized asbestos-induced disease Am J Ind Med 1996;29:183-5.

7. Merler E, Vineis P, Alhaique D, et al. Occupational cancer in Italy. Environ Health Perspect 1999;107:259-71.

8. Seaton A. Diagnosing and managing occupational disease. BMJ 1995;310:1282.

9. Teschke K, Barroetavena MC. Occupational cancer in Canada: what do we know? Can Med Assoc J 1992;147:1501-7.

10. Lax MB, Grant WD, Manetti FA, et al. Recognizing occupational disease--taking an effective occupational history. Am Fam Physician 1998;58:935-44.

11. Abdool Karim SS, Dilraj A. Reasons for under-reporting of notifiable conditions. S Afr Med J 1996;86:834-6.

12. Elms J, O'Hara R, Pickvance $S$, et al. The perceptions of occupational health in primary care. Occup Med (Lond) 2005;55:523-7.

13. Harber $\mathbf{P}$, Merz B. Time and knowledge barriers to recognizing occupational disease $\mathrm{J}$ Occup Environ Med 2001;43:285-8.

14. Saliba ML, larmarcovai $G$, Souville $M$, et al. Les médecins face à la santé au travail : une étude qualitative dans le Sud-Est de la France. Rev Epidemiol Sante Publique 2007:55(5):376-81.

15. Bates D. Environmental health risks and public policy: decision-making in free societies. Seattle, WA: University of Washington Press, 1994.

16. Guidotti TL. Apportionment in asbestos-related disease for purposes of compensation. Ind Health 2002;40:295-311.

17. Henderson DW, Jones ML, De Klerk N, et al. The diagnosis and attribution of asbestos-related diseases in an Australian context: report of the Adelaide Workshop on Asbestos-Related Diseases, October 6-7, 2000. Int J Occup Environ Health 2004;10:40-6.

18. Bruske-Hohlfeld I. Occupational cancer in Germany. Environ Health Perspect 1999;107:253-8.

19. Chapple A, Ziebland S, McPherson A. Stigma, shame, and blame experienced by patients with lung cancer: qualitative study. BMJ 2004;328:1470.

20. Levy B. Occupational health. Boston: Little, Brown, 1988.

21. Corneille 0, Leyens J, Yzerbyt V. Judgeability concerns: the interplay of information, applicability, and accountability in the overattribution bias. J Pers Soc Psychol 1999;76:377-87.

22. Aulagnier M, Verger P, Ravaud JF, et al. General practitioners' attitudes towards patients with disabilities: the need for training and support. Disabil Rehabil 2005;27:1343-52.

23. Bocquier A, Verger $P$, Basdevant $A$, et al. Overweight and obesity: knowledge, attitudes, and practices of general practitioners in France. Obes Res 2005;13:787-95.

24. Gerbert B, Maguire BT, Bleecker T, et al. Primary care physicians and AIDS. Attitudinal and structural barriers to care. JAMA 1991;266:2837-42.

25. Moatti JP, Souville M, Escaffre N, et al. French general practitioners' attitudes toward maintenance drug abuse treatment with buprenorphine. Addiction 1998;93:1567-75

26. Brugere J, Thebaud-Mony A, Pezerat $\mathrm{H}$, et al. [Occupational cancers: notification, compensation and prevention]. Bull Cancer 1994;81:14-21.

27. Burstein JM, Levy BS. The teaching of occupational health in US medical schools: little improvement in 9 years. Am J Public Health 1994;84:846-9.

28. Levy BS. The teaching of occupational health in United States medical schools: five year follow-up of an initial survey. Am J Public Health 1985;75:79-80.

29. Paraponaris A, Verger $P$, Desquins $B$, et al. Delivering generics without regulatory incentives? Empirical evidence from French general practitioners about willingness to prescribe international non-proprietary names. Health Policy 2004;70:23-32.

30. Verger P, Brabis PA, Kovess V, et al. Determinants of early identification of suicidal ideation in patients treated with antidepressants or anxiolytics in general practice: a multilevel analysis. J Affect Disord 2007;99:253-7.

31. Kelly JA, St Lawrence JS, Smith S Jr, et al. Stigmatization of AIDS patients by physicians. Am J Public Health 1987;77:789-91. 


\section{Appendix}

\section{Physician practices, attitudes and self-perceived role}

variables

- Mean daily number of consultations or visits

- Year of graduation

- Continuing medical education in the field of occupational health (yes/no)

- Asks questions about past exposure (never/sometimes, often, very often)

- Number of occupational disease medical certificates filed in the past 5 years

- Has seen patients with asbestos-related lung cancers during the past 12 months in consultations (never/sometimes, often, very often)

- Feels able to answer patients' questions about occupational health (never/sometimes, often, very often)

- Thinks that complexity of the lists of compensable OD is a barrier to reporting occupational diseases (totally disagree, partially disagree, partially agree, totally agree)

- Thinks that lack of knowledge of administrative procedures is a barrier to reporting occupational diseases (totally disagree, partially disagree, partially agree, totally agree)

- Thinks that lack of knowledge of reporting criteria is a barrier to reporting occupational diseases (totally disagree, partially disagree, partially agree, totally agree)

- Thinks that lack of time is a barrier to reporting occupational diseases (totally disagree, partially disagree, partially agree, totally agree)

- Thinks that occupational disease detection is part of his/her role (totally disagree, partially disagree, partially agree, totally agree)

- Thinks that completing occupational disease medical certificates is part of his/her role (totally disagree, partially disagree, partially agree, totally agree)

(1) (d); (2) (d); (3) (b); (4) (e) 